\title{
Dynamic Line-Scan Thermography for the Inspection of Paper-Based Materials: A Case Study Focused on an Ancient Book Cover ${ }^{\dagger}$
}

\author{
Hai Zhang ${ }^{1, *}$, Stefano Sfarra ${ }^{2}$, Clemente Ibarra-Castanedo ${ }^{1}$ and Xavier P. V. Maldague ${ }^{1}$ \\ 1 Computer Vision and Systems Laboratory (CVSL), Department of Electrical and Computer Engineering, \\ Laval University, QC G1V 0A6, Canada \\ 2 Department of Industrial and Information Engineering and Economics, University of L'Aquila, \\ I-67100 L'Aquila, Italy \\ * Correspondence: hai.zhang.1@ulaval.ca \\ + Presented at the 15th International Workshop on Advanced Infrared Technology and Applications (AITA \\ 2019), Florence, Italy, 17-19 September 2019.
}

Published: 18 September 2019

\begin{abstract}
This work is focused on the use of line-scan thermography (LST) method for the inspection of an ancient book cover. Three widely used image post-processing techniques (i.e., pulsed phase thermography, partial least square thermography and principal component thermography) were applied to the acquired thermal sequences. Flash thermography (FT) anticipated the LST results in order to have a comparison of the results. It was concluded that LST is an effective technique for paper-based materials, and it can additionally provide a higher image contrast if compared to classical FT technique.
\end{abstract}

Keywords: non-destructive evaluation (NDE); line-scan thermography (LST); paper-based materials

\section{Introduction}

The conservation and restoration of books, manuscripts, documents and ephemera is an activity dedicated to the preservation and protection of items of historical and personal value made primarily from paper, parchment, and leather. When applied to cultural heritage conservation activities are generally undertaken by a conservator-restorer. Scientists may help in this task by providing information concerning the subsurface state of the object under inspection and, therefore, trying to understand the main causes of deterioration [1]. This is quite "difficult" in paper-based materials such as book cover because the agents of deterioration are many (i.e., fire, water, gas and heat, dust and neglect, pests and other vermin and mishandling). Non-destructive inspection (NDI) may offer a solution for any diagnostic team to find the non-visible degradation processes and, in fact, some case studies have recently been proposed, analyzed and discussed [2,3], also thank to the use of infrared vision [1].

Infrared vision is a broad term, which can encompass the imaging techniques classed on the basis of the wavelengths from $0.75 \mu \mathrm{m}$ (just past the visible spectrum) up to $1000 \mu \mathrm{m}$ (in the terahertz band, right before the microwaves). Generally speaking, near-infrared (NIR) region (roughly $0.75 \mu \mathrm{m}$ to $3 \mu \mathrm{m}$ ) and the thermal-bands named infrared thermography (IRT, roughly $3 \mu \mathrm{m}$ to $14 \mu \mathrm{m}$ ) are both widely attractive to thick objects (i.e., artworks) because they have the potential to provide interesting subsurface information [4].

Anyway, IRT shows some disadvantages for the inspection of large artworks; indeed, it is difficult to probe a large-scale specimen (above all when it is non-planar) because the traditional IRT 
system usually uses a stationary configuration. In the latter case, the images obtained should be later reassembled by following a mosaicking procedure. In this regard, it is fundamental to apply a smart equipment (useful, e.g., for the inspection of large-scale paper-based materials), based on an anthropomorphous robot which is able to overcome the advantages provided by the well-known scanners, implemented for several years into the cultural heritage field.

In this work, the authors uses line-scan thermography (LST) to investigate an ancient book cover. It was selected as laboratory scale product. Pulsed phase thermography (PPT), partial least square thermography (PLST) and principal component thermography (PCT) were applied to the acquired thermal sequences. FT was used as term of comparison for the LST results. It was concluded that LST is an effective technique for paper-based materials, and it may additionally provide a higher image contrast if compared to classical FT technique. This work may contribute to develop the feasibility of LST technique for inspections in museums of large cultural heritage objects.

\section{Specimen}

The inspected book cover, dating back presumably to nineteenth century, has dimensions equal to $0.090 \times 0.165 \times 0.036(\mathrm{~m})$ and weighs about $0.6 \mathrm{Kg}$. The front and rear facets appear discolored and stained (Figure 1) and, moreover, infested by pests, since a diffuse series of small holes are evident. The book cover was realized with boards larger than the text block. In case books with similar bookbinding structure are stored vertically, gravity gradually pulls the unsupported fore edges down, thus causing - as in the present case-their warp. Spines are not present on the lateral side of the inspected book [1].

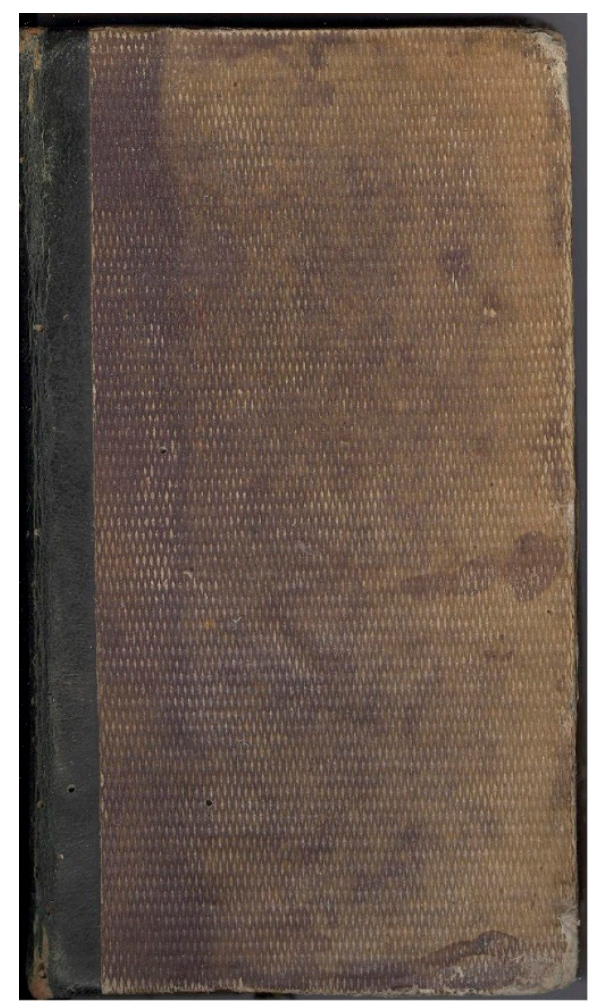

Figure 1. Inspected book cover.

\section{Flash and Dynamic Line-Scan Thermography (FT \& LST)}

FT configuration uses two photographic flashes as heating source (Figure 2a). It produces a transient thermal pulse on the specimen surface. Heat diffuses through the specimen by conduction, and a part return to the surface. As time elapses, the temperature of the surface decreases uniformly for a specimen without internal defects. On the contrary, internal discontinuities act as resistances to heat flow, which changes the diffusion rate by producing irregular temperature patterns. These 
patterns can be detected by an IR camera; only a $\Delta \mathrm{T}$ of a few $\mathrm{mK}$ is needed when modern thermal imaging instruments are used [5].

However, FT set-up is difficult for the in-line inspection of large-scale specimens. In this work, LST was used (Figure 2b) with the aim to introduce its advantages. Instead of the stationary set-up of the FT modality, LST uses a dynamic line heating source operated by an anthropomorphous robot. The line heating source covers the whole large-scale specimen both in time and space, while the camera moves after the heating source synchronously to gather the thermal signals. More information regarding the system can be found in [6].

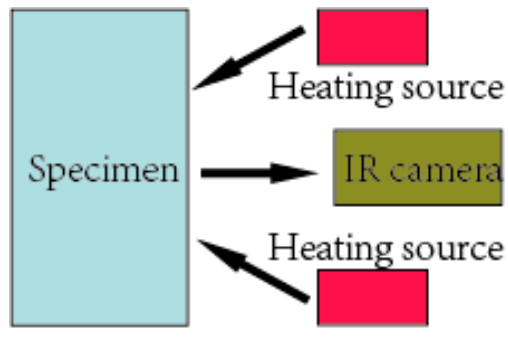

(a)

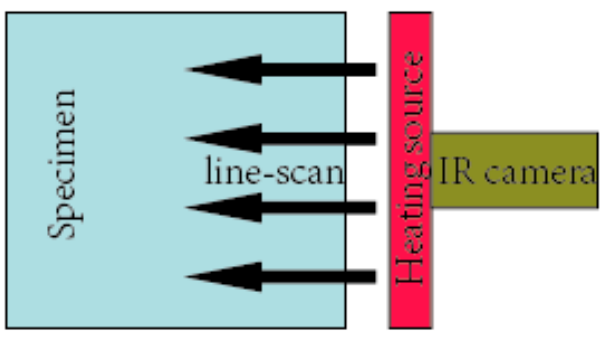

(b)

Figure 2. Schematic configurations for: (a) FT, and (b) line-scan thermography.

\section{Results}

Figure 3 shows the flash thermography result after PCT processing. The latter reorganizes data into new components that take into account the main spatiotemporal variances of the sequence. Through this conventional technique, the natural defects in the book cover are shown in the thermal image clearly. The visual inspection was a fundamental step to distinguish the defects found. These defects are due to some of the factors listed into the Introduction section.

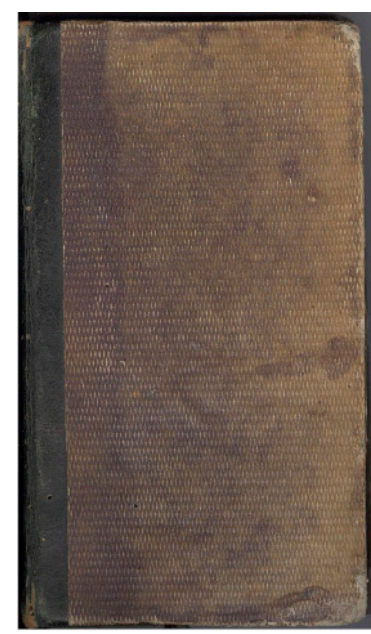

Photo

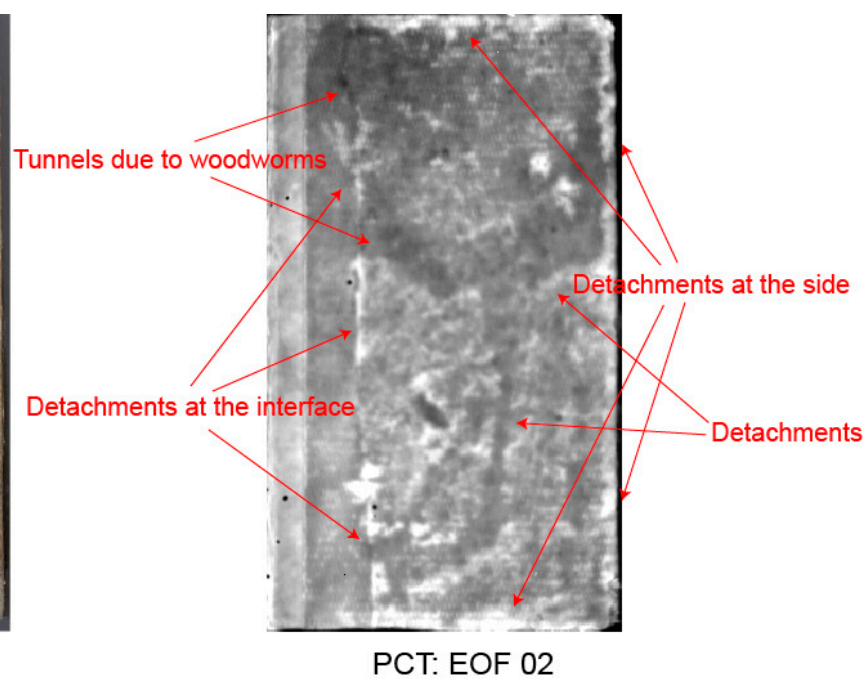

PCT: EOF 02

Figure 3. FT result compared to the visible image.

Figure 4 shows the LST results after the application of the PCT technique. It is possible to see how detachments are located mostly on the edge areas, as well as at the interface between two different materials. This is a clue concerning the position of the book in time. Mechanical forces, mostly force of gravity and sliding friction, may cause such defects. Incorrect hygrothermic conditions of preservation can be at the base of the biological attacks signaled in Figure 3 (right side). Same things can be said concerning the results provided by LST (Figure 4). 


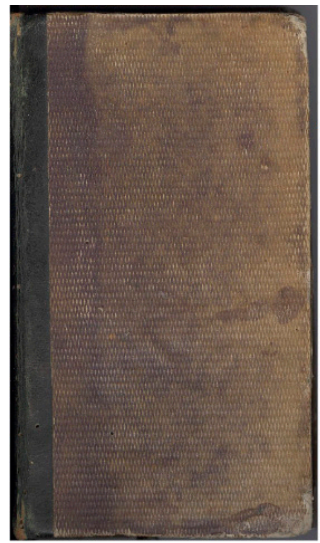

Photo

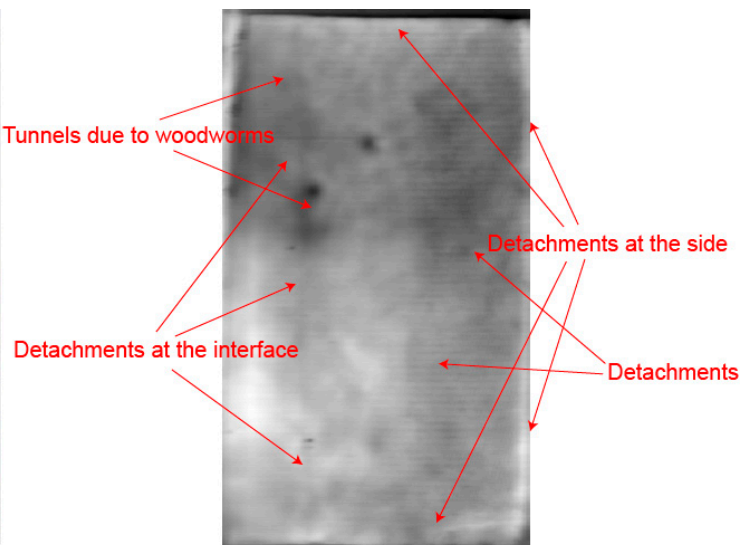

РCT: EOF 02

Figure 4. LST results based on PCT technique.

\section{Conclusions}

In this study, FT and LST approaches are adopted for defect detection in an ancient bookbinding. It should be noted that LST can be applied for large paper-based samples shown vertically, e.g., in museums. This is a pros of such technique. Analyzing the results presented herein it is possible to see how both FT and LST provide the main defects (caused by biological or mechanical problems) on which the restorer should focus the attention during the restoration work.

Author Contributions: Conceptualization, H.Z. and S.S.; methodology, H.Z. and C.I.-C.; software, H.Z. and C.I.C.; validation, X.P.V.M.; formal analysis, H.Z.; investigation, H.Z. and C.I.-C.; resources, S.S., and X.P.V.M.; data curation, H.Z., S.S. and C.I.-C.; writing-original draft preparation, H.Z. and S.S.; writing-H.Z. and S.S.; visualization, H.Z. and S.S.; supervision, X.P.V.M.; project administration, X.P.V.M.; funding acquisition, X.P.V.M.

Funding: This research was funded by the Natural Sciences and Engineering Research Council (NSERC) Canada through a Discovery grant.

Conflicts of Interest: The authors declare no conflict of interest.

\section{References}

1. Sfarra, S.; Regi, M.; Tortora, M.; Casieri, C.; Perilli, S.; Paoletti, D. A multi-technique nondestructive approach for characterizing the state of conservation of ancient bookbindings. J. Therm. Anal. Calorim. 2018, 132, 1367-1387.

2. Mercuri, F.; Orazi, N.; Paoloni, S.; Cicero, C.; Zammit, U. Pulsed Thermography Applied to the Study of Cultural Heritage. Appl. Sci. 2017, 7, 1010.

3. Mercuri, F.; Gnoli, R.; Paoloni, S.; Orazi, N.; Zammit, U.; Cicero, C.; Marinelli, M.; Scudieri, F. Hidden text detection by infrared thermography. Restaurator 2013, 34, 195-211.

4. Ibarra-Castanedo, C.; Khodayar, F.; Klein, M.; Sfarra, S.; Maldague, X.; Helal, H.; Tayoubi, M.; Marini, B.; Barré, J.C. Infrared vision for artwork and cultural heritage NDE studies: principles and case studies. Insight-Non-Destr. Test. Cond. Monit. 2017, 59, 243-248.

5. Maldague, X.P. Nondestructive Evaluation of Materials by Infrared Thermography; Springer Science \& Business Media: Berlin, Germany, 2012.

6. Peeters, J.; Ibarra-Castanedo, C.; Khodayar, F.; Mokhtari, Y.; Sfarra, S.; Zhang, H.; Maldague, X.; Dirckx, J.; Steenackers, G. Optimised dynamic line scan thermographic detection of CFRP inserts using FE updating and POD analysis. NDT E Int. 2018, 93, 141-149. 